MOJTABA MOUSAZADEH GILANDEH, M.Sc. ${ }^{1}$

E-mail: mousazadehgilandeh.1781839@studenti.uniroma1.it

SARI SHARIF ALI, M.Sc. ${ }^{2}$

E-mail: sarisharif@yahoo.com

MOHAMMAD JAVAD GOODARZI, M.Sc. ${ }^{3}$

E-mail: mohammadjavad.goodarzi@alum.sharif.edu

NAHID AMINI, M.Sc. ${ }^{4}$

E-mail: nahid.amini@srbiau.ac.ir

HASSAN LATIFI, M.Sc. ${ }^{4}$

(Corresponding author)

E-mail: hassan.latifi@srbiau.ac.ir

${ }^{1}$ Department of Civil and Industrial Engineering

Dipartimento di Ingegneria Civile e Industriale (DICI)

Sapienza University of Rome

Via Eudossiana 18, Rome 00184, Italy

2 Dept. of Civil Engineering

University of Guilan, Rasht, Iran

${ }^{3}$ School of Civil Engineering

Sharif University of Technology

Azadi Ave, Tehran, Iran

${ }^{4}$ Department of Civil Engineering,

Science and Research Branch

Islamic Azad University, Tehran, Iran
Traffic Planning

Original Scientific Paper

Submitted: 26 Apr. 2020

Accepted: 25 Aug. 2020

\title{
MODELLING OF QUEUE LENGTH IN FREEWAY WORK ZONES - CASE STUDY KARAJ-TEHRAN FREEWAY
}

\begin{abstract}
In this study, the traffic parameters were collected from three work zones in Iran in order to evaluate the queue length in the work zones. The work zones were observed at peak and non-peak hours. The results showed that abrupt changes in Freeway Free Speed (FFS) and arrival flow rate caused shockwaves and created a bottleneck in that section of the freeway. In addition, acceleration reduction, abrupt change in the shockwave speed, abrupt change in the arrival flow rate and increase in the percentage of heavy vehicles have led to extreme queue lengths and delay. It has been found that using daily traffic data for scheduling the maintenance and rehabilitation projects could diminish the queue length and delay. Also, by determining the bypass for heavy vehicles, the delay can be significantly reduced; by more than three times. Finally, three models have been presented for estimating the queue length in freeway work zones. Moreover, the procedure shown for creating a queue length model can be used for similar freeways.
\end{abstract}

\section{KEYWORDS}

freeway work zone; modelling of queue length; traffic parameters; Karaj-Tehran freeway case study.

\section{INTRODUCTION}

Road maintenance and rehabilitation require the creation of work zones. In general, there are two types of work zones: a completely or a partially closed road. In case of partially closed road, one or more lanes are closed. Work zones on freeways lead to traffic disturbances and delays which causes an increase of the time of travel, vehicle depreciation and fuel consumption [1]. On freeways and urban highways, the maintenance and rehabilitation projects result in creating long queues especially during rush hours. On the other hand, one of the major factors which reduce road safety and increase delay for all users is queueing. In the developed countries many studies have been conducted or are being carried out on the causes of creating queues $[2,3,4]$ while in the developing countries, this has been less considered. By considering the increasing number of vehicles and maintenance and rehabilitation projects, the necessity to study the creation of queues is increasingly emphasized [5]. This study aims to present the queue length models in work zones and to analyse each of their constituent factors. Because 
of the multifaceted nature of queueing on freeways, determining the causes of creating long queues is generally difficult. In Iran, as a developing country, an authentic database has not been provided. Therefore, the field data collection is very important. One of the goals of this study is to present the models of queue length in work zones. The results can be effective in keeping a balance between the traffic volume and delay. Data gathering included three parts. First, some sections of the freeway were selected in the peak and non-peak traffic hours in order to compare the obtained results, and then the required information from the recorded videos was extracted. Next, the achieved diagrams of the traffic parameters such as speed, flow rate, density and queue length have been evaluated. Finally, the obtained queue length models have been compared with the actual data.

\section{LITERATURE REVIEW}

The review of the previous studies on work zones reveals that the delay has been investigated more than any other parameter and the focus has been on the costs of the users. Shibuya et al. [6] showed in a study that the delay resulting from the rate of change of velocity includes 35 to 40 percent of the total delay in the work zones. Nam and Drew [7] presented a numerical model of the queue. The drawback of this model is that it predicts the delay less than the actual amount. This model has some shortcomings in comparison with the kinematic model. Son [8] presented a model for estimating the queue length. The results showed that the delay due to queueing was less than the delay due to lower speed. Migtez et al. [9] investigated the speed limitation in the work zones. They revealed that speed reduction to a maximum of $16 \mathrm{~km} /$ hour, reduces accidents. Ullman and Dudek [10] suggested a theory method for estimating the queue length. This method predicts the queue length and delays less than the actual amount according to the data obtained from the field information. They suggested a macroscopic model based on speed, density, and flow rate. Renata et al. [11] studied 17-speed reduction patterns in the work zone and showed that cars and heavy vehicles follow similar patterns. Weng and Meng [12] provided a model for the estimation of capacity in freeway work zone using field information of 18 US work zones. This model has the ability to estimate the total capacity after the speed reduction and queuing. The capacity of the work zone is dependent on several factors including speed limits, driver conditions, weather conditions, length of work zone, position of the closed lane, lane width, time and period of maintenance and rehabilitation project, number of lanes open in the work zone, number of lanes closed in the work zone, types of road, slope of work zone, percentage of heavy vehicles and intracity or suburban work zone. Jian et al. [13] estimated the capacity and speed in the work zone. For this purpose, they estimated traffic flow parameters using video recording in 15-minute intervals and presented a model. The results of this study revealed that the obtained model estimated the capacity less than the actual value but computed the speed with more accuracy. Von der Heiden and Geistefeldt [14] evaluated the field information of 18 long work zones and 111 short work zones in Germany. For long work zones, a distribution function of capacity and for short work zones, a multivariate non-linear regression were used for modeling. The obtained models presented more accurate results than the ones obtained by the other methods. Comert [15] using VISSIM software at intersections showed that the delay resulting from numerical queueing theory has been estimated lower than its actual value. Therefore, they proposed using a combination of simulations and queueing theory. Benekohal et al. [16] investigated traffic parameters in freeway work zones in the state of Illinois in the US. In this research, the delay in the work zones is composed of two components, which can be classified as delay due to queueing and delay due to lower speed. The delay due to lower speed is because of the bottleneck influenced by a number of factors such as small width of the lanes, small lateral clearance, small width of the hard shoulder and speed limit. Delay due to queueing is due to high demand of the work zones, which is calculated based on the cumulative arrival and departure numbers of vehicles over time and using the queueing theory by Highway Capacity Manual (HCM 2000) [17] application. If the demand exceeds the capacity of a work zone, a queue is created. As shown in Figures 1 and 2, the values of delay and queue length (number of vehicles in the queue) are calculated using the queueing theory which is used in the present study [16].

And as shown in Figure 1:

$n_{i+1}=n_{i}+V_{i+1}-C_{a d j} \cdot N_{o p}$

where,

$n_{i+1}$ - number of vehicles in queue at the end of (i+1)-th hour;

$n_{i} \quad$ - number of vehicles in queue at the end of 
the $i$-th hour;

$V_{i+1}$ - total demand in $(i+1)$-th hour [vph];

$C_{a d j}$ - adjusted capacity [vphpl];

$N_{O P}$ - number of lanes open in the work zone.

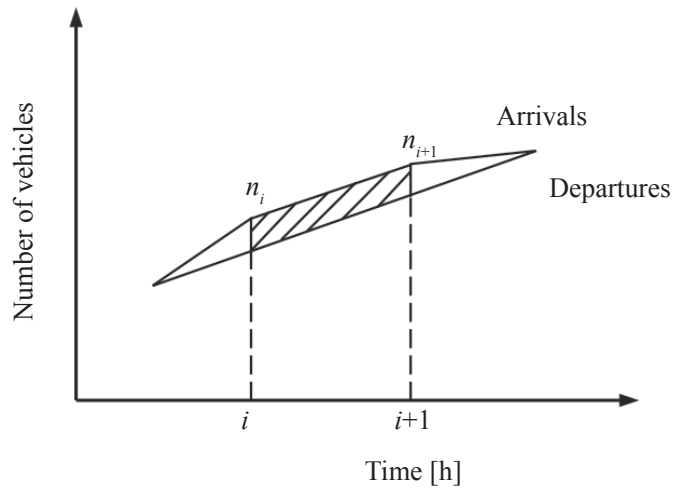

Figure 1 - Average delay due to queueing

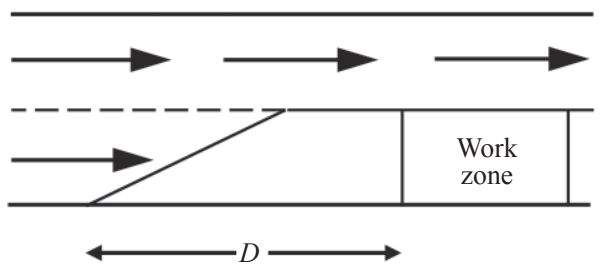

Figure 2-Determining D in a work zone

And, given the stacked queue length at the end of $i$-th hour $\left(Q_{s i}\right)$ and the value of $D$, the queue length for each lane is obtained by the following equations:

$D<\frac{Q_{s i}}{N_{o p}} \rightarrow Q_{i}=D+\frac{Q_{s i}-D \cdot N_{o p}}{N_{n r}}$

$D>\frac{Q_{s i}}{N_{o p}} \rightarrow Q_{i}=\frac{Q_{s i}}{N_{o p}}$

where,

$Q_{i} \quad$ - queue length at the end of the $i$-th hour [ft];

$Q_{s i} \quad$ - stacked queue length at the end of the $i$-th hour [ft];

$N_{o p}-$ number of lanes open in the work zone;

$N_{n r}^{o p}$ - number of lanes open before the work zone;

$D$ - distance from the work activity area to the beginning of the taper [ $\mathrm{ft}]$.

Estimate the delay due to queuing using Equation 4:

$d_{q}=\sum_{i=0}^{t-1} \frac{n_{i}+n_{i+1}}{2}$

where,

$d_{q}$ - delay due to queueing [veh-hours];

$t$ - number of hours of queueing;

$n_{i}$ - number of vehicles in queue at the end of the the $i$-th hour;

$n_{i+1}-$ number of vehicles in queue at the end of the $(i+1)$-th hour.

\section{CASE STUDY - WORK ZONE LOCATIONS}

The work zones were specifically created for this study in Karaj-Tehran freeway by Annual Average Daily Traffic (AADT) of 217,084 vehicles. In this study, video recording was used to collect data. The data mainly contain the number of vehicles passing through the work zones, including cars, vans, buses, minibuses, trailers and trucks (light and heavy) per unit time and the speed of vehicles at a specified distance $[17,18]$. This distance was considered as 50 metres. This was done in 1-minute intervals. The rush hours in the three areas are from 8:00 a.m. to 10:00 a.m. Figure 3 shows the location of the work zones. As shown in Figure 4, two lanes of the eightlane freeway (four lanes in each direction) remained closed in the work zones. These areas were video recorded before, in the middle and at the end of the work zones. Several different cars were marked in each lane and the time they passed through the specified intervals was obtained using the image timer. The images of Work zones 1 and 2 are displayed in Figure 5. Moreover, Adobe Premiere software was used in order to analyse the three work zones. The image of the procedure for Work zone 3 is presented in Figure 6. The information of the three work zones are as follows:

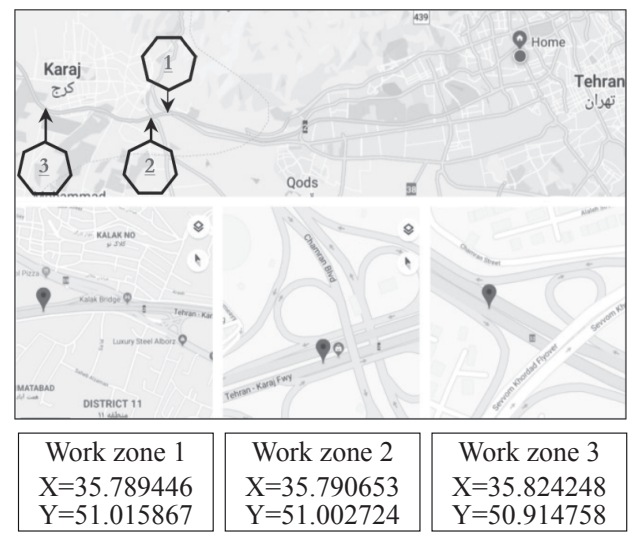

Figure 3 - Location of the work zones

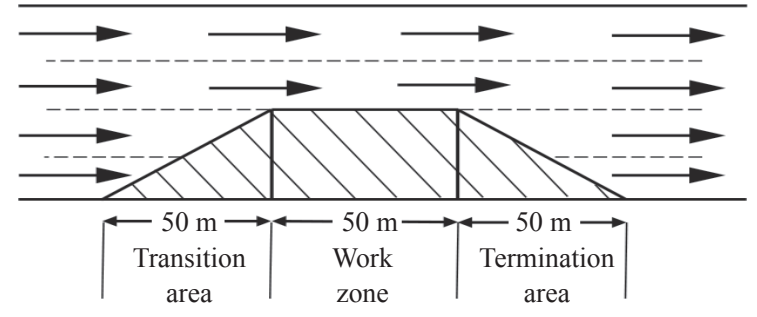

Figure 4-Schematic image of freeway lanes in the work zones 


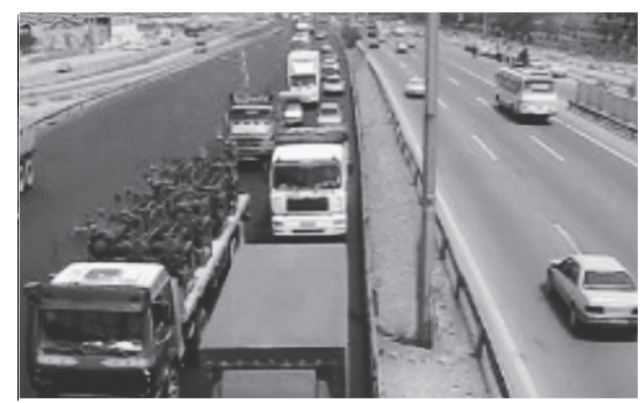

Work zone 1

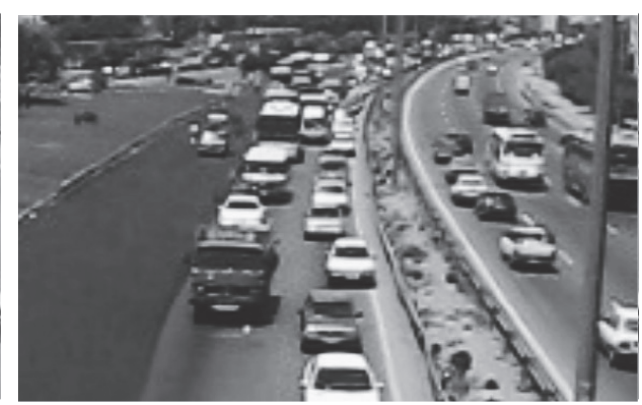

Work zone 2

Figure 5 - The images of Work zones 1 and 2

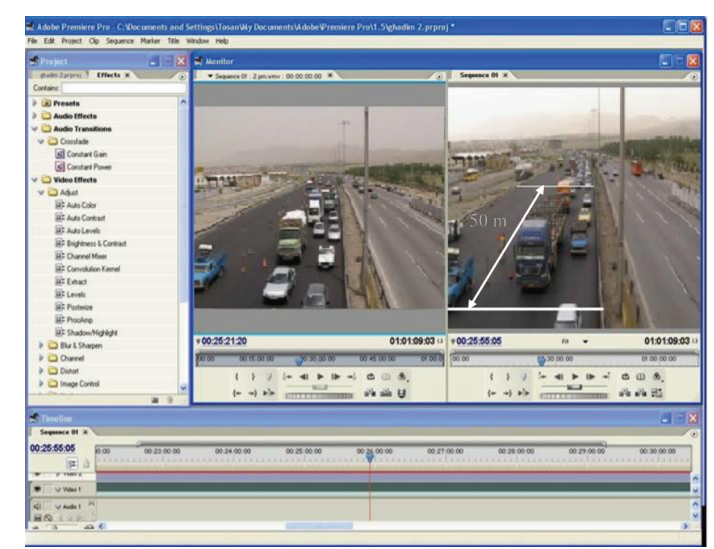

Figure 6 - The image of Adobe Premiere software including Work zone 3

Work zone 1: The first area was located at Karaj-Tehran freeway in the west-east direction, the before Kalak Bridge. The camera recording was done on Saturday, 21 January 2017 from 9:00 a.m. to 10:00 a.m. Work zone 2: The second area was located at Karaj-Tehran freeway in the west-east direction, before the Chamran Blvd. The camera recording was done on Wednesday, 1 February 2017 from 10:45 a.m. to 11:45 a.m.

Work zone 3: The third area was located at KarajTehran freeway in the west-east direction, before the Sevvom Khordad Flyover. The camera recording was carried out on Thursday, 2 February 2017 from 9:35 a.m. to 10:35 a.m.

\section{TRAFFIC PARAMETERS}

\subsection{Speed change models}

In order to measure the speed, the required time for passing a distance of 50 metres was measured $[17,18]$. Next, the space mean speed was calculated using the following equation:

$$
V_{s}=\frac{N L}{\sum_{i=1}^{N} t_{i}}
$$

where $V_{s}$ is the space mean speed $(\mathrm{km} / \mathrm{h}), L$ is the length of the area $(\mathrm{km})$, and $N$ is the number of measuring times and $t$ is the time for passing the distance (hour).

At the peak traffic hours, if traffic demand exceeds the service capacity, it causes a shockwave and creates a bottleneck in that section of the freeway $[17,18]$. In Figures $7-9$, speed wavy changes are

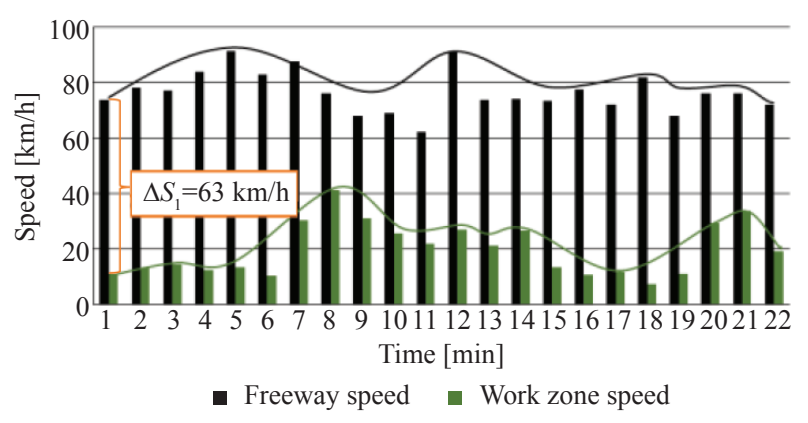

Figure 7 - Speed changes in Work zone 1

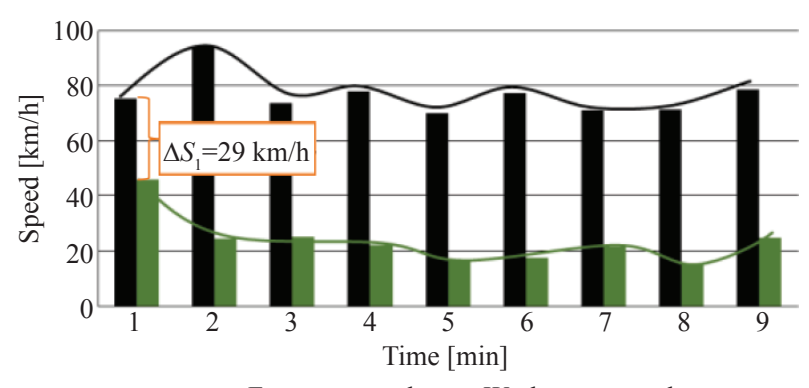

- Freewav sneed a Work zone sneed

Figure 8-Speed changes in Work zone 2

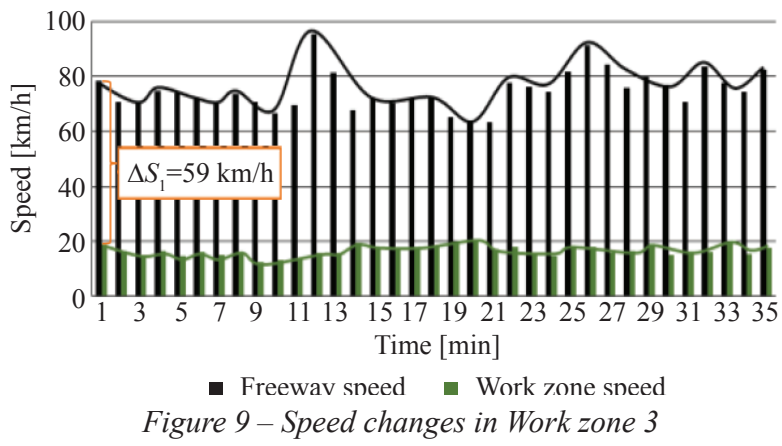


displayed. These wavy curves are more intense in arrival areas of the work zones. It indicates the shockwaves had been more effective in transition areas. Also as illustrated in Figures 7-9, in the first minutes, the differences of average speed between the transition and termination areas $\left(\Delta \mathrm{S}_{1}\right)$ for Work zones 1, 2 and 3 are 63, 29 and 59, respectively. It indicates that in Work zone 1 , the effect of speed reduction plays a significant role in queue length increase. As presented in section "Queue length", Equation 6, the queue length model of Work zone 1, the effect of the acceleration reduction $(a)$ on queue length is characterized. As result of the shockwave, according to Figures 9 and 14, the average speed reduction is about 58 kilometres per hour, while the flow rate of the work zone reaches from 1,550 to 2,300 vehicles per hour. In all curves, with the increasing flow rate, the average speed increases.

\subsection{Flow rate - speed models}

As shown in Figures 10-15, six fitting types were done on the flow rate - speed data and the equation and detection coefficient of the equation $\left(R^{2}\right)$ are written on each one. In Figures 14 and 15 the congested and uncongested flow rates are detectable. In uncongested flow rate, with the increasing flow rate, the speed remains approximately constant. At the flow rate between 1,200 to 1,500 vehicles per hour, the speed is 70 kilometres per hour.

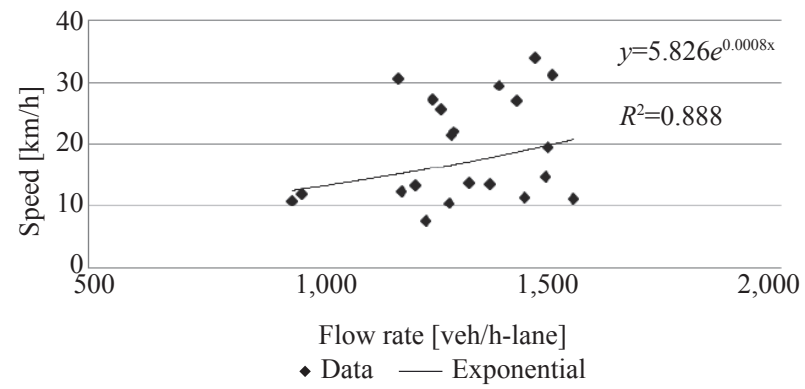

Figure 10 - Speed-congested flow rate in Work zone 1

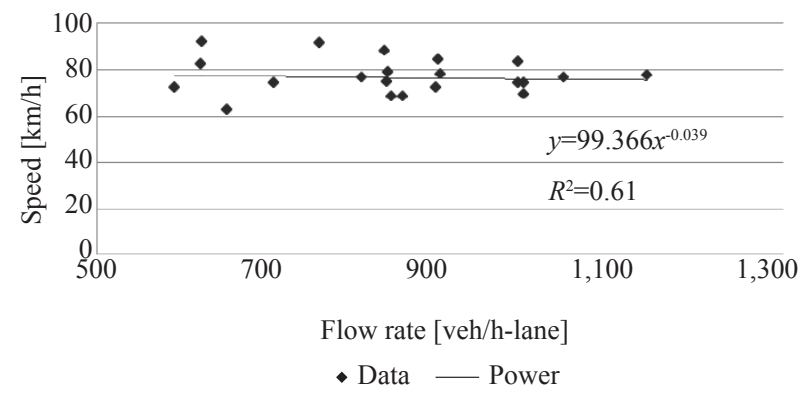

Figure 11 - Speed-uncongested flow rate in Work zone 1

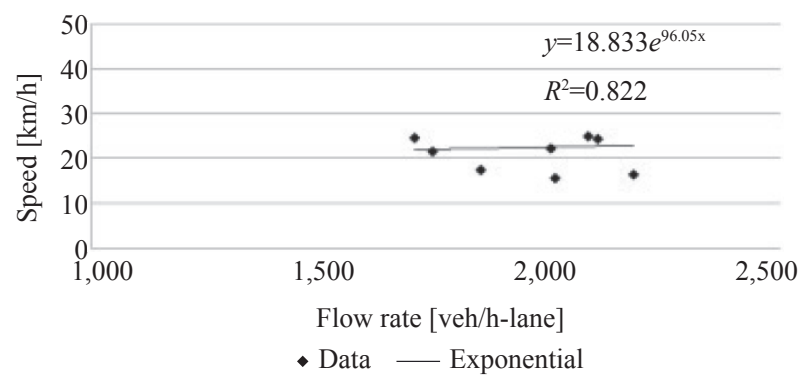

Figure 12 - Speed-congested flow rate in Work zone 2

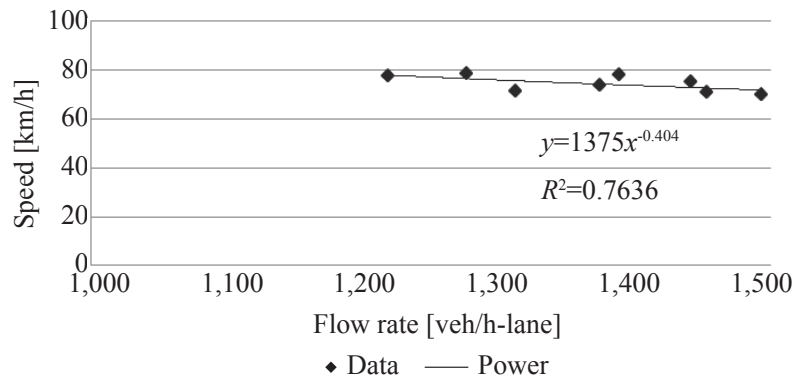

Figure 13 -Speed-uncongested flow rate in Work zone 2

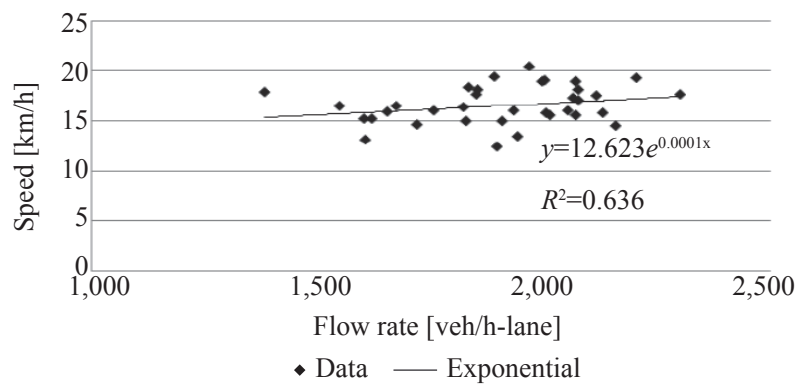

Figure 14 - Speed-congested flow rate in Work zone 3

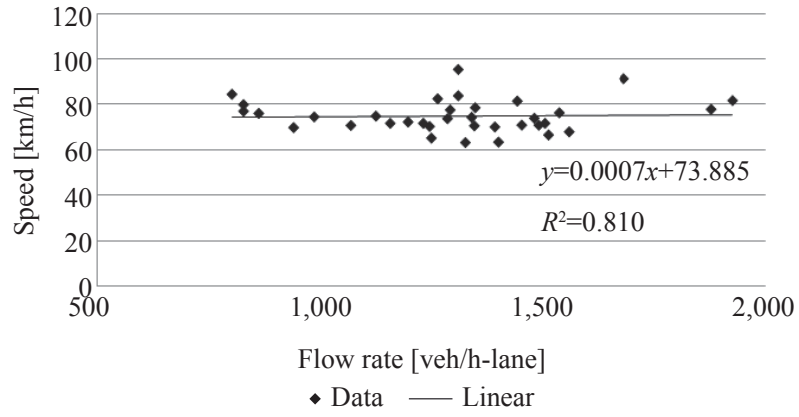

Figure 15 - Speed-uncongested flow rate in Work zone 3

\subsection{Speed - density models}

Speed and density are reversely related. The normal shape of speed - density is a linear curve [18]. According to Figures 16-18, since speed is reduced suddenly because of the necking of the freeway, the curves have two parts. When the density goes to zero, the mean speed goes towards the Freeway Free Speed (FFS) $[17,18]$. If the density goes to the highest value, the speed goes towards zero. The speed change curve is shown in Figures 16-18. As illustrated 
in Figures 7-9, the abrupt change in speed divides the curves of Figures 16-18 in two parts. In other words, significant speed reduction has caused abrupt increase in density.

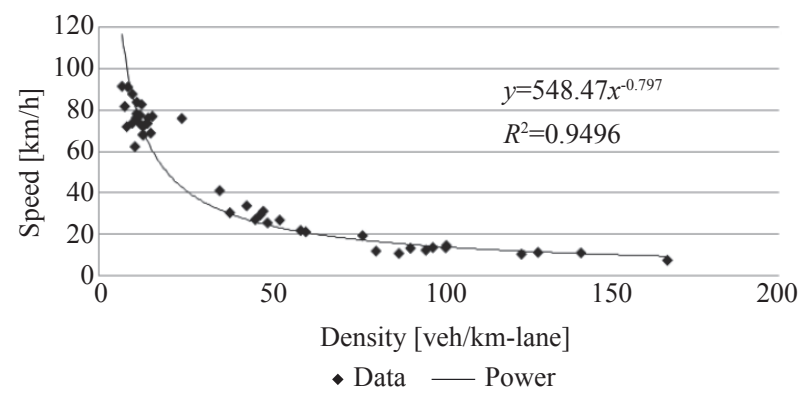

Figure 16-Speed - density in Work zone 1

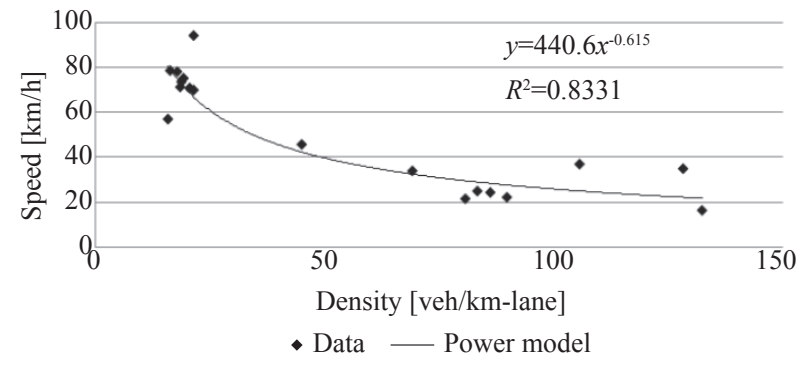

Figure 17 - Speed - density in Work zone 2

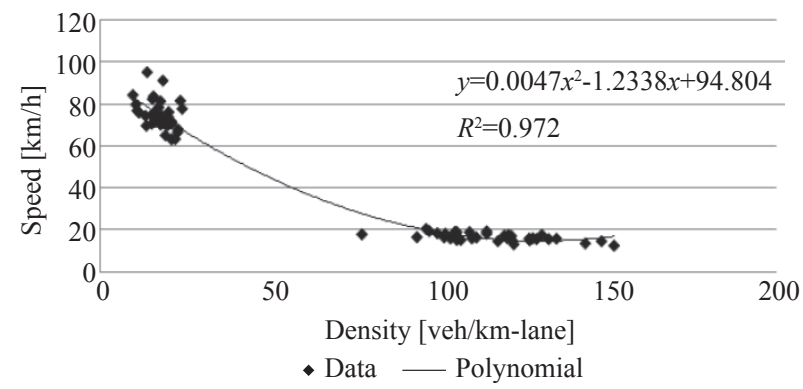

Figure 18 - Speed - density in Work zone 3

\subsection{Flow rate - density models}

The relation between density and flow rate is as a second-degree function. If the density is zero, the flow rate is zero and if the density has its maximum value i.e. when the vehicles are stopped, the flow rate is zero. Also, if the density is zero, there is no vehicle on the road. In Figures 19-21, the flow rate change curves as a function of density have been shown. In these curves, the tangent on the curve gives the shockwave speed $\left(W_{u}\right)$. The carried out fittings in all work zones are appropriate. As shown in Figures 19-21, the detection coefficients for these areas are $0.62,0.53$ and 0.7 , respectively. In work zone 3 , because of the shockwave, the curve has two parts.
In Figures 19-21, the left part of the curve indicates the state at which the speed is relatively high (about 80 to 85 kilometres per hour). In this part, the shockwave speed $\left(W_{u}\right)$ between every two points can be obtained by dividing the flow rate by density. As illustrated in Figure 21, high shockwave speed in the first minutes and afterwards, high change in the shockwave speed $\left(W_{u}\right)$ caused an abrupt increase in the density and subsequently increased the queue length. As presented in Section "Queue length", Equation 8, the queue length model of Work zone 3; the effect of the shockwave speed $\left(W_{u}\right)$ on queue length is characterized. The right part of the curve corresponds to the state at which the density has

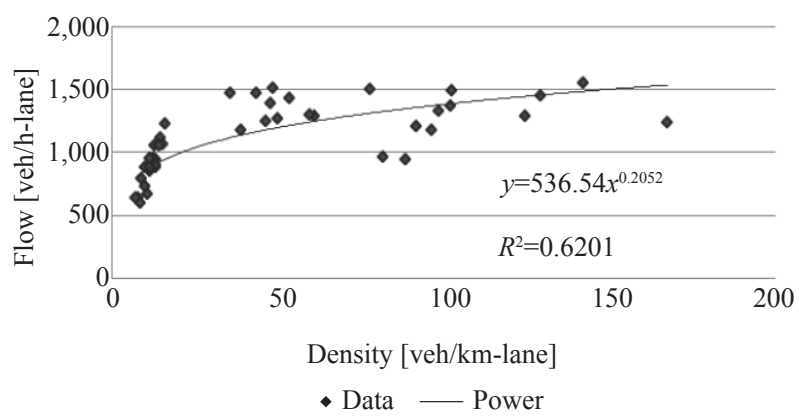

Figure 19 - Data fitness using flow rate - density statistics in Work zone 1

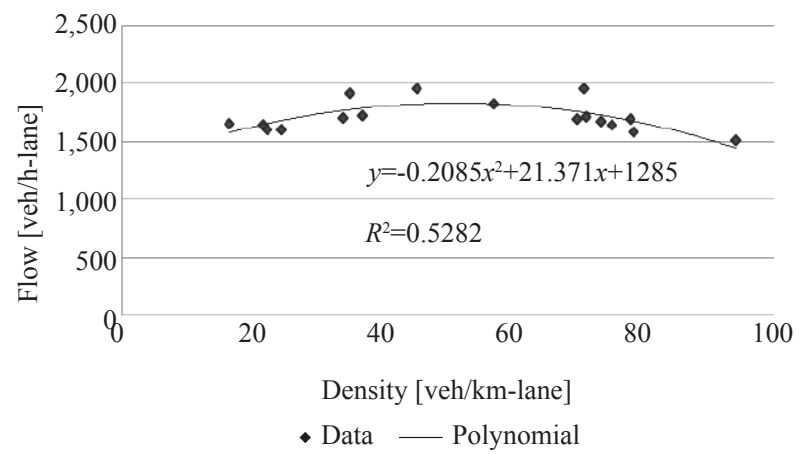

Figure 20 - Data fitness using flow rate - density statistics in Work zone 2

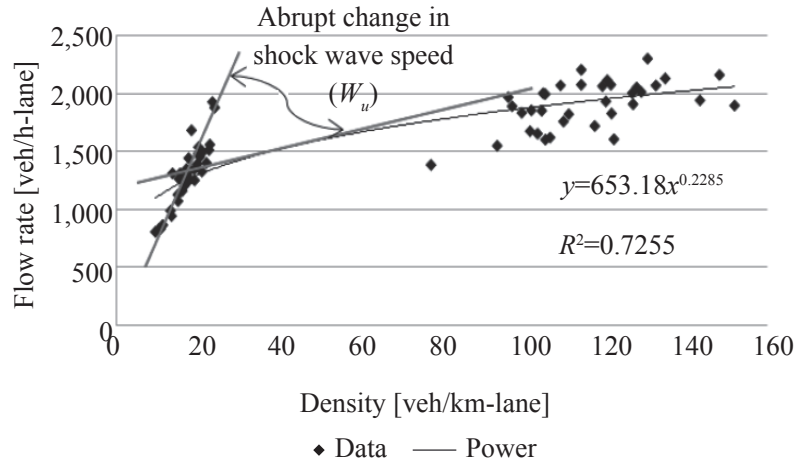

Figure 21-Data fitness using flow rate - density statistics in Work zone 3 
increased and as result, the flow rate is decreasing, and the queue length is increasing. In Figure 21, the density is between 130 to 160 vehicles per kilometre. Thus, it can be found that the queue length is proportional to the density and shockwave speed. High changes in flow rate and low changes in density lead to increasing the queue length in the work zones.

\subsection{Queue length}

In the queueing theory, the cumulative arrival departure flow rate curves are used for estimating the queue length. In Table 1, the numbers of arriving and

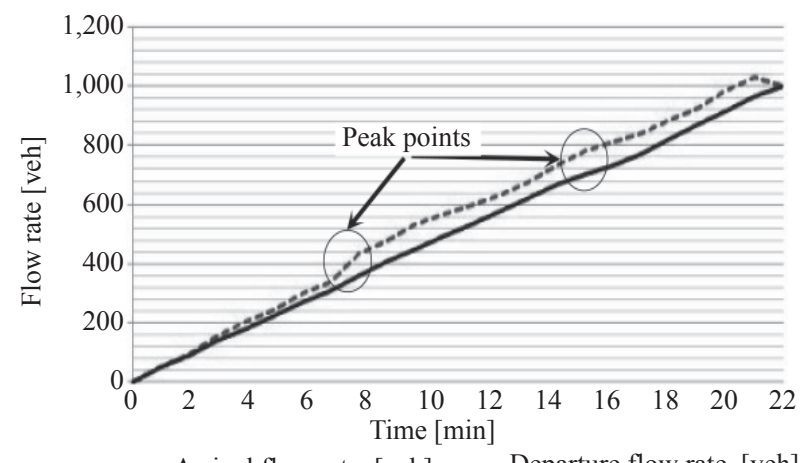

..... Arrival flow rate $[\mathrm{veh}]$ - Departure flow rate $[\mathrm{veh}]$

Figure 22 - Diagram of cumulative arrival and departure flow rates in Work zone 1

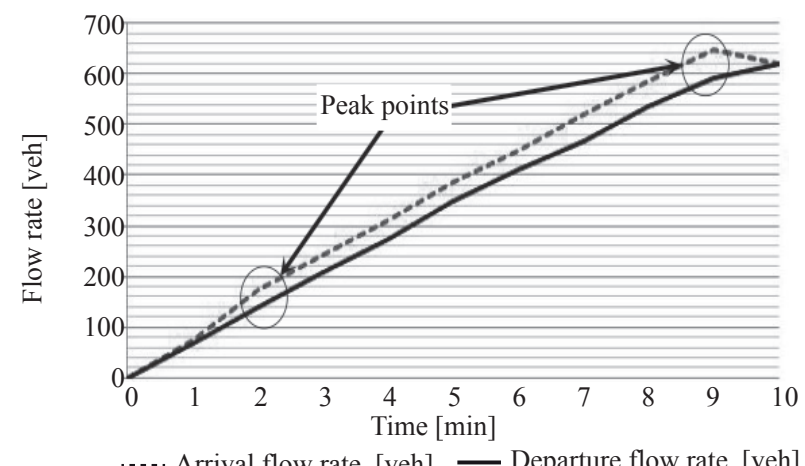

Figure 23 - Diagram of cumulative arrival and departure flow rates in Work zone 2

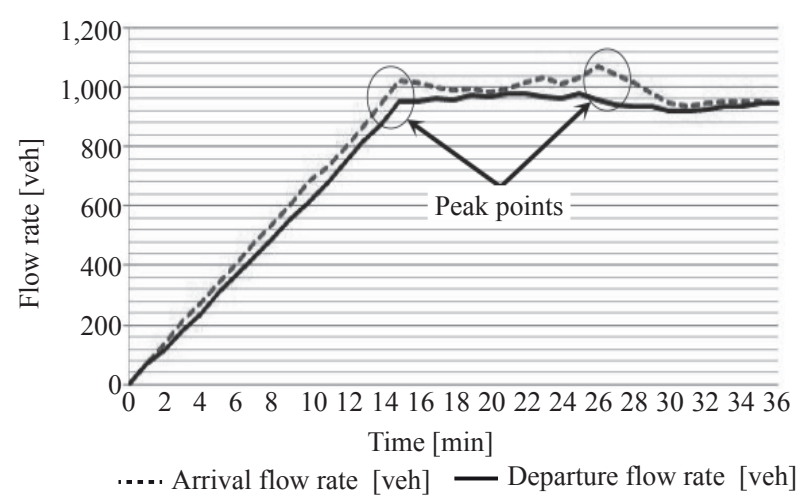

Figure 24 -Diagram of cumulative arrival and departure flow rates in Work zone 3 departing vehicles in the work zones have been presented. Using these tables, the curves in Figures 22-27 were drawn.

Using Figures 22-24, and measuring the area between the two curves, it is possible to obtain the total delay by the queueing theory [11]. Figures 2527 reveal the number of vehicles in the queue. In these figures, the positive and negative slopes of the curves indicate the increased and decreased queue length relative to the previous state, respectively. In all the three work zones the abrupt increase in arrival flow rate caused peak points of queue length curves. For instance, for Work zone 1, considering Figure 25 there are peak points in the $8^{\text {th }}$ and $16^{\text {th }}$ minute. That is because according to Figure 22, there are abrupt increases in the arrival

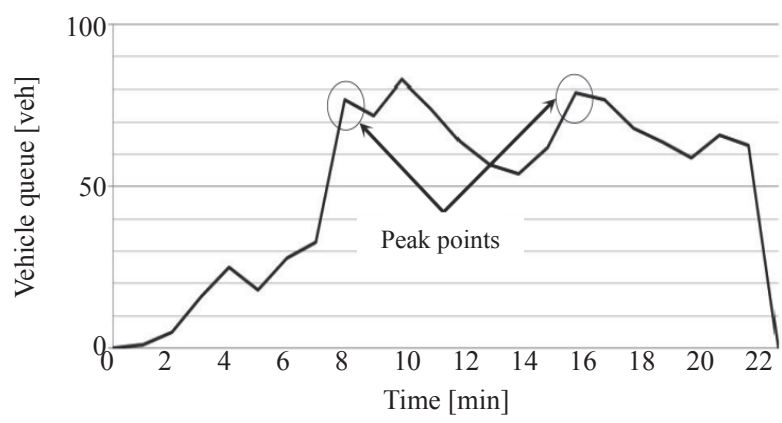

Figure 25 -Diagram of queue length changes in Work zone 1

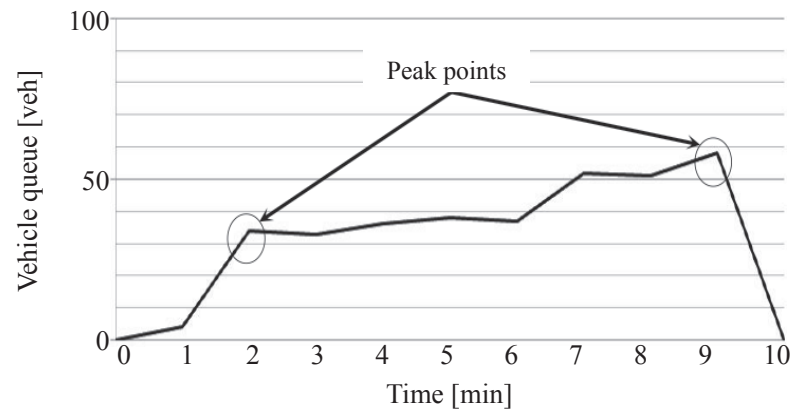

Figure 26 - Diagram of queue length changes in Work zone 2

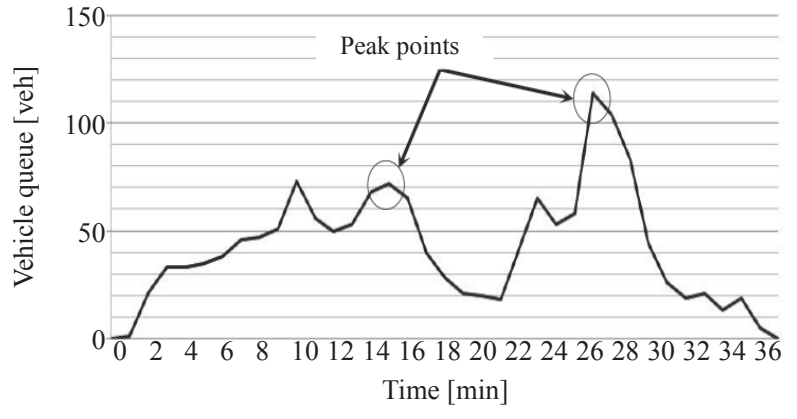

Figure 27 - Diagram of queue length changes in Work zone 3 
flow rate in these minutes. The percentage of heavy vehicles has been considerable and it indicates that the number of heavy vehicles has great impact on the traffic quality. Figures 25-27 show that in some points, the curve has local peaks. The main reasons for increasing the queue length at these times are heavy vehicles and the increase in the arrival flow rate to the work zone. Finally, using Table 1, in one-minute intervals, the results of Table 2 have been obtained.

According to the results in Table 2, and comparison of the data for Work zones 1 and 2, it can be concluded that with increasing the flow rate and the

Table 1 -Cumulative arrival and departure flow rates in the work zones

\begin{tabular}{|c|c|c|c|c|c|c|c|c|c|}
\hline \multirow[b]{2}{*}{$\begin{array}{l}\text { Time } \\
{[\mathrm{min}]}\end{array}$} & \multicolumn{2}{|c|}{ Work zone 1} & \multicolumn{2}{|c|}{ Work zone 2} & \multicolumn{5}{|c|}{ Work zone 3} \\
\hline & $\begin{array}{l}\text { Arrival } \\
\text { rate } \\
{[\text { veh] }}\end{array}$ & $\begin{array}{c}\text { Departure } \\
\text { rate } \\
{[\text { veh }]}\end{array}$ & $\begin{array}{c}\text { Arrival rate } \\
{[\text { veh] }}\end{array}$ & $\begin{array}{c}\text { Departure } \\
\text { rate } \\
\text { [veh] }\end{array}$ & $\begin{array}{c}\text { Arrival } \\
\text { rate } \\
{[\mathrm{veh}]}\end{array}$ & $\begin{array}{c}\text { Departure } \\
\text { rate } \\
{[\text { veh }]}\end{array}$ & $\begin{array}{l}\text { Time } \\
{[\mathrm{min}]}\end{array}$ & $\begin{array}{c}\text { Arrival rate } \\
{[\text { veh] }}\end{array}$ & $\begin{array}{c}\text { Departure } \\
\text { rate } \\
{[\text { veh }]}\end{array}$ \\
\hline 1 & 53 & 52 & 73 & 69 & 68 & 67 & 23 & 1,031 & 966 \\
\hline 2 & 97 & 92 & 173 & 139 & 140 & 119 & 24 & 1,013 & 960 \\
\hline 3 & 158 & 142 & 242 & 209 & 215 & 182 & 25 & 1,034 & 976 \\
\hline 4 & 206 & 181 & 311 & 275 & 271 & 238 & 26 & 1,071 & 957 \\
\hline 5 & 245 & 227 & 386 & 348 & 345 & 310 & 27 & 1,045 & 941 \\
\hline 6 & 298 & 270 & 447 & 410 & 407 & 369 & 28 & 1,016 & 933 \\
\hline 7 & 342 & 309 & 520 & 468 & 476 & 430 & 29 & 980 & 936 \\
\hline 8 & 435 & 358 & 586 & 535 & 541 & 494 & 30 & 946 & 920 \\
\hline 9 & 480 & 408 & 649 & 591 & 608 & 557 & 31 & 937 & 918 \\
\hline 10 & 533 & 450 & - & - & 684 & 611 & 32 & 945 & 924 \\
\hline 11 & 567 & 493 & - & - & 731 & 675 & 33 & 950 & 937 \\
\hline 12 & 599 & 535 & - & - & 796 & 746 & 34 & 954 & 935 \\
\hline 13 & 635 & 578 & - & - & 868 & 815 & 35 & 951 & 946 \\
\hline 14 & 679 & 625 & - & - & 946 & 878 & - & - & - \\
\hline 15 & 732 & 670 & - & - & 1,021 & 949 & - & - & - \\
\hline 16 & 780 & 701 & - & - & 1,016 & 951 & - & - & - \\
\hline 17 & 810 & 733 & - & - & 1,002 & 962 & - & - & - \\
\hline 18 & 842 & 774 & - & - & 987 & 959 & - & - & - \\
\hline 19 & 886 & 822 & - & - & 993 & 972 & - & - & - \\
\hline 20 & 928 & 869 & - & - & 986 & 966 & - & - & - \\
\hline 21 & 984 & 918 & - & - & 994 & 976 & - & - & - \\
\hline 22 & 1,031 & 968 & - & - & 1,018 & 977 & - & - & - \\
\hline
\end{tabular}

Table 2 - Summary of delay information

\begin{tabular}{|c|c|c|c|c|c|c||}
\hline $\begin{array}{c}\text { Work zone } \\
\text { number }\end{array}$ & $\begin{array}{c}\text { Average queue } \\
\text { length [veh] }\end{array}$ & $\begin{array}{c}\text { Time of } \\
\text { queueing }\end{array}$ & $\begin{array}{c}\text { Percentage of } \\
\text { heavy vehicles }\end{array}$ & $\begin{array}{c}\text { Total delay } \\
\text { [veh-min] }\end{array}$ & $\begin{array}{c}\text { Average departure flow } \\
\text { rate of vehicles [veh/min] }\end{array}$ & $\begin{array}{c}\text { Average arrival flow rate } \\
\text { of vehicles [veh/min] }\end{array}$ \\
\hline \hline 1 & 53 & 22 & 25 & 1,166 & 43.54 & 46.86 \\
\hline 2 & 39 & 9 & 15 & 351 & 65.4 & 71.5 \\
\hline 3 & 44 & 35 & 15 & 1,540 & 27 & 27.17 \\
\hline
\end{tabular}


reduction of the percentage of heavy vehicles, the queue length will be reduced and as a result, the total delay of vehicles decreases. As seen in Table 2, the delay has decreased from 1,166 to 351 vehicles per minute (i.e. three times). Moreover, by considering Work zones 2 and 3, where the percentage of heavy vehicles is equal, it is observed that the delay in Work zone 3 is higher, because it is closer to the rush hours (about 8:00 a.m. to 10:00 a.m.).

In this paper, using a non-linear multivariate regression model, the quantity of an unknown variable is determined using the variables defined. Backward Elimination method is used to select the variables. First, independent variables were entered into the regression equation. Then the variables with lower correlation coefficients were eliminated from the equation. Finally, the main parameters for modeling are as follows:

$Q$ - number of stopped vehicles in the queue;

$V_{A}$ - speed of arriving vehicles to the bottleneck $[\mathrm{km} / \mathrm{min}]$;

$V_{D}$ - speed of vehicles departing the bottleneck $[\mathrm{km} / \mathrm{min}]$;

$k_{D}$ - density of the departure vehicles from the bottleneck [vehicles/km];

$k_{A}-$ density of the arrival vehicles to the bottleneck [vehicles $/ \mathrm{km}$ ];

$q_{D}$ - flow rate of the vehicles departing from the bottleneck [vehicles/min];

$q_{D h}$ - flow rate of heavy vehicles departing from the bottleneck [vehicles/min];

$q_{A}$ - flow rate of vehicles arriving to the bottleneck [vehicles/min];

$q_{A h}$ - flow rate of heavy vehicles arriving to the bottleneck [vehicles/min];

$W_{u}$ - speed of the shockwave resulting from the speed reduction $[\mathrm{km} / \mathrm{min}]$;

$a$ - acceleration reduction of the vehicles $\left[\mathrm{km} / \mathrm{min}^{2}\right]$.

The models for the three work zones are as follows:

$$
\begin{aligned}
& Q_{1}=259.137-0.023 a+0.114\left(20.547 q_{D}\right)+ \\
& +0.425\left(29.822 \ln \left(q_{D}-q_{A}\right)\right)-7.605 \ln \left(k_{D}-k_{A}\right) \\
& Q_{2}=163.109-1.848\left(q_{D h}-q_{A h}\right)-1.42 q_{D}-77.387 V_{D} \\
& Q_{3}=197.594-3.742 W_{u}-1.151\left(k_{D}-k_{A}\right)+e^{\left[-13.719\left(\frac{k_{A}}{k_{D}-K_{A}}\right)\right]}
\end{aligned}
$$

A summary of the data from each model is presented in Table 3. By these data, the appropriateness of the models has been evaluated. According to
Table 3, the models have high appropriateness and are acceptable. Figures 28 -30 show the comparison between the actual data and the models.

Table 3 - Summary information from the three models

\begin{tabular}{|c|c|c|c|}
\hline $\begin{array}{c}\text { Work zone } \\
\text { number }\end{array}$ & Adjusted $R^{2}$ & $F$ & Sign \\
\hline \hline 1 & 0.611 & 9.246 & 0 \\
\hline 2 & 0.919 & 31.298 & 0.001 \\
\hline 3 & 0.590 & 9.727 & 0 \\
\hline
\end{tabular}

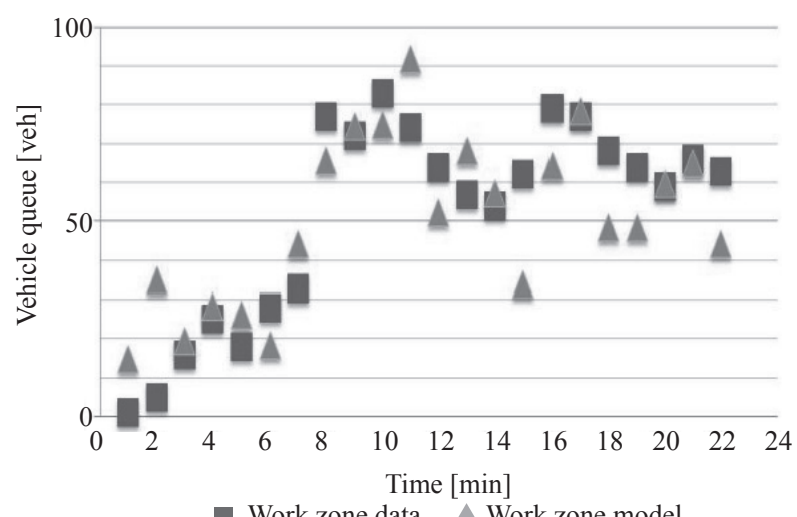

Figure 28 - Comparison between actual data and the modelWork zone 1

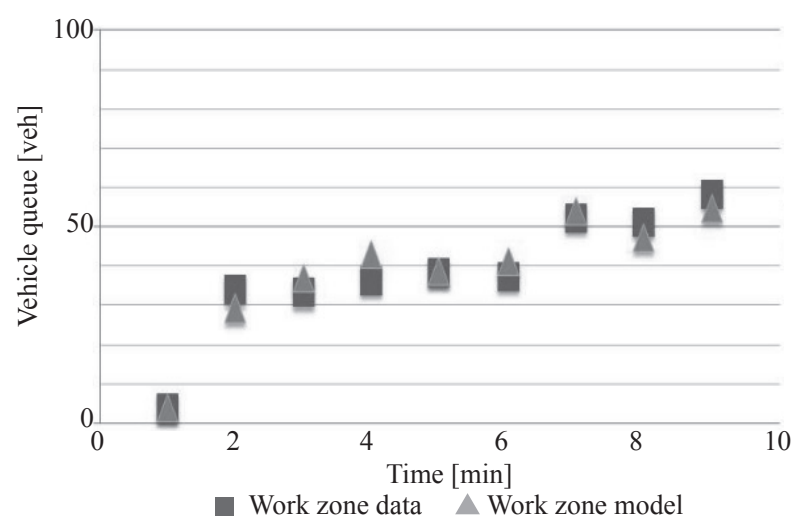

Figure 29 - Comparison between actual data and the modelWork zone 2

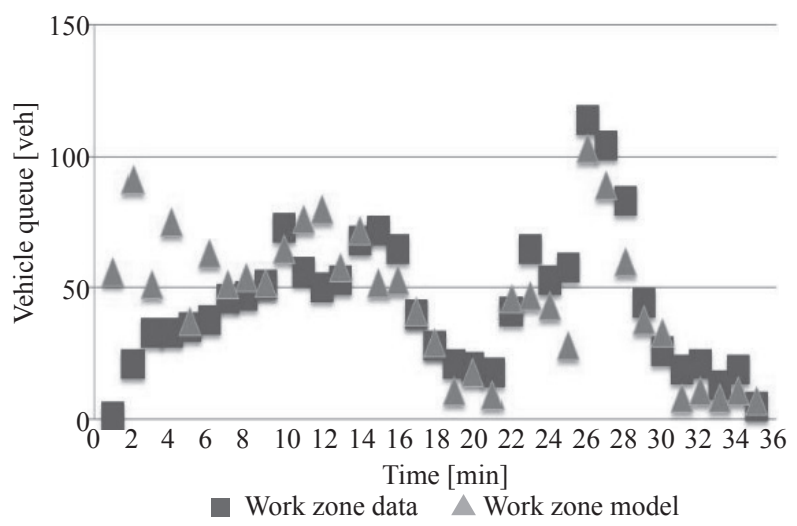

Figure 30 - Comparison between actual data and the modelWork zone 3 


\section{DISCUSSION}

This paper presents the methodology (that is built on the queueing theory mentioned earlier in the section on the literature review) for computing the queue length and delay due to queueing. The methodology is illustrated by a step-by-step procedure for computing the delay and queue length. This methodology can be used to compute the delays and queue length in work zones and to ensure that the maximum delays comply with the requirements of the jurisdiction. In addition, according to our investigations, each work zone in a specific freeway has its own queue length model, but the procedure shown for creating a queue length model can be used for similar freeways. On the other hand, the effects of the number difference between cars and heavy vehicles, peak and non-peak hours, acceleration reduction, abrupt change in the shockwave speed and abrupt change in arrival flow rate on the delay and queue length were evaluated.

Further studies are recommended to collect the field data to quantify the queue length and delay due to the narrow lane widths, lateral clearances, speed enforcement, work intensity and other factors. Also, it is recommended that the queue length and delay be computed in a work zone of a specific part of a freeway with and without determining a bypass for heavy vehicles and comparing the results.

\section{CONCLUSION}

In the present study, after evaluating the traffic parameters and modelling of queue length in Karaj-Tehran freeway work zones, the following conclusions have been drawn:

- The results have shown that factors such as acceleration reduction (a) and shockwave speed (Wu) which were more intense in Wsork zones 1 and 3 , respectively, were also effective in their queue moldels.

- The workzones that have taken place nearer the peak hour and with higher percentage of heavy vehicles, have featured significantly more delay.

- At the peak time and if the traffic demand exceeds the service capacity, it caused shockwaves and created a bottleneck in that section of the freeway. Thus, by using daily traffic data and scheduling the maintenance and rehabilitation projects, it can be possible to reduce the queue length.
- The queue length is proportional to the density and shockwave speed. Abrupt change of shockwave speed causes abrupt change of density and subsequently increased queue length.

- High percentage of heavy vehicles have had a great impact on increasing the queue length. Then, by determining the bypass for heavy vehicles, one can obtain the reduction of queue length, delay and the cost of road users. Also, it has been shown that by determining the bypass for heavy vehicles, the delay can be significantly reduced; more than three times.

- According to our investigations, each work zone in a specific freeway has its own queue length model, but the procedure shown for creating a queue length model can be used for similar freeways.

- With increasing the flow rate at the arrival and departure sections of the work zones, the queue length decreased and as a result, the total delay decreased. This total delay reduction has caused the reduction of the travel time and increase of the speed at the departing section.

- Abrupt changes in speed and arrival flow rate have caused shockwaves in the work zones. In general, with decreasing the shockwave speed, long queues are created. Therefore, it can be concluded that changing the working hours in the work zone to non-peak traffic hours causes an increase in the average speed. It is also possible to reduce the travel time and delay in freeways by controlling traffic so that the arrival flow rate from the upstream is less than the capacity level of the work zone.
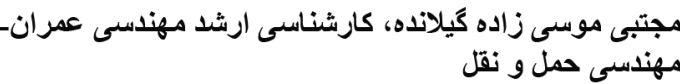

دانشكده مهندسى عمر ان و صنايع، دانشخاه سايينز ا، رم، ايتاليا mousazadehgilandeh.1781839@studenti.uniromal.it سارى شريف على، كارشناسى ارشد مهندسى عمران- مهندسى راهو ترابرى

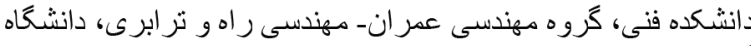

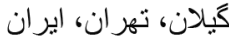
sarisharif@yahoo.com

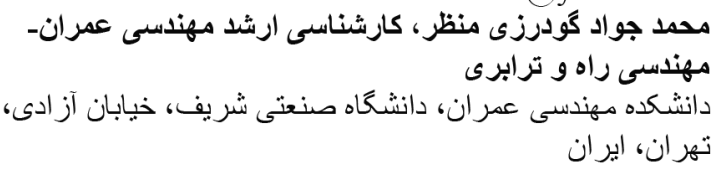
mohammadjavad.goodarzi@alum.sharif.edu ناهيد امينى، كارشناسى ارشد مهندسى عمران- مهندسى راهو ترابرى تصائ

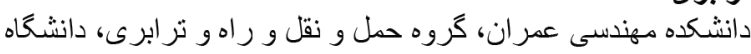
آز اد اسلامى واحد علوم و تحقيقات، تهر ان، ايران nahid.amini@),srbiau.ac.ir 
